\title{
Creativity in Business Education: A Review of Creative Self-Belief Theories and Arts-Based Methods
}

\author{
Sogol Homayoun ${ }^{1}$ and Danah Henriksen ${ }^{2, *}$ (D) \\ 1 Thunderbird School of Global Management, Arizona State University, Phoenix, AZ 85069, USA; \\ sogol.homayoun@thunderbird.asu.edu \\ 2 Mary Lou Fulton Teachers College, Division of Educational Leadership and Innovation, Arizona State \\ University, Phoenix, AZ 85069, USA \\ * Correspondence: danah.henriksen@asu.edu; Tel.: +1-517-256-2344
}

Received: 8 September 2018; Accepted: 13 November 2018; Published: 20 November 2018

\begin{abstract}
Creativity has become one of the most sought-after skills from graduates across business and industry. It is therefore imperative to infuse creativity training within business programs of study and professional development experiences, to remind people of their eternally curious and creative nature. The objective of this paper is to explore the literature around theories of creative potential and performance-including creative identity, creative mindset, and creative self-efficacy. We consider perspectives that reveal that creativity is a mindset predicated on beliefs and ways of thinking. Educational psychology literature and theories of creative self-belief illustrate how creative identity, mindset, and self-efficacy form the core of an individual's belief system to think, act, and develop creatively in the world. This connects to the potential of arts-based methods as a means to infuse creative learning into business education. We illustrate how our findings can be put into practice by sharing an example of an art-based intervention that is currently in progress to develop creative capacity among students in an internationally known business program. We conclude with the idea that its incumbent upon business education, professional development, and training to incorporate methodologies that enhance creative capacity by initially eliminating or minimizing self-perceived limitations in people, such as fear, negative personal judgement, and chattering of the mind-and theories of creative self-belief provide a foundation that can undergird arts-based methods toward this goal.
\end{abstract}

Keywords: creativity; business; education; training; professional development; creative thinking; theories; arts; arts-based methods; innovation

\section{Introduction}

There has been increasing discussion about the need for more creative thinkers in business and industry [1]. Florida [2], Schlee and Harich [3], and others have advocated the need to cultivate a creative workforce, to develop innovative thinkers that can address complex 21st century problems and challenges.

The fact that creativity is perceived as being variable, inimitable and subjective, has often made it vulnerable to being marginalized in education-since traditional educational structures are often based around certainty, grades, and single-answer thinking. Yet, creative thought processes are necessary criteria for accomplishment in our complex, interdependent society [4]. Globalization has led to exponential increases in knowledge and technology. This has implications for education-especially in business fields, which thrive on the need to innovate, problem solve, and nimbly shift with societal moves. Daniel Pink [5] illustrates the heightening value of creative abilities, stating: 
Today, the defining skills of the previous era-the "left brain" capabilities that powered the Information Age-are necessary but no longer sufficient. And the capabilities we once disdained or thought frivolous-the "right brain" qualities of inventiveness, empathy, joyfulness, and meaning-increasingly will determine who flourishes and who flounders. (p. 3)

Given the popularity of business education as a field of study, and the need for creative thinking in the business workforce, it is important to consider the intersection of creativity and business education. Boulocher-Passet et al. [6] encourage initiatives for creativity in business schools, and specifically note that there are few existing studies that teach creativity to business students with the aim of leveraging student perception on creativity. There are many good reasons to support the promotion of creative thinking in business contexts or training, and the rationale for this has been established by existing literature, organized around the ways that creativity addresses problems and sustains economic development [7-9], supports human wellness and expression [10,11], and builds productive confidence [12,13]. In this article, we focus on this issue of creativity in business education in a literature review around theories of creative self-beliefs and the potential of arts-based methods in business.

The objective of this paper is to explore and review key literature around theories of creative potential and performance-which includes creative identity, creative mindset, and creative self-efficacy. We begin by defining what we mean by creativity. Plucker et al. [14] note that one of the common weaknesses of creativity research and scholarship has been a problem of lack of definition, with only $38 \%$ of articles about creativity in academic journals even providing any working definition at all. Thus, we seek to ground our ideas in a common perspective on the construct. We build upon theories from education and psychology which discuss the importance of supporting creative capacity. We relate these ideas to creative self-beliefs-including creative mindset, creative identity, and creative self-efficacy. Further, we focus on the use of arts-based methods in business education and training as being one of several important approaches to building creative confidence and capacities. We provide some current and future directions for research in this area, and describe an in-progress research intervention, as an example of an approach that seeks to enhance creative capacity (through arts-based and other methods) among international business program students.

\section{Defining and Grounding Creativity as a Construct}

Creativity is an ancient construct, yet formal research on the concept has only been prevalent since the latter half of the 20th century [15]. While creativity is thought of as a subjective term, most research around it defines it as having several core components. First, a creative idea, process or product is novel—it brings something into play that either did not exist before or, at least, is relatively new for its context. Cropley [16] asserts, however, that a novel idea with no potential use cannot be taken as "creative", because novelty does not guarantee that something will be effective $[17,18]$. So, the most common definition suggests that creativity is a process of coming up with designs, artifacts, objects, programs, or ideas that are both "novel" (original, new, fresh, etc.) and "effective" (useful, productive, or of some value to others). Another key characteristic, according to Sternberg and O'Hara [19], involves "task appropriateness." Creative things (ideas, products, processes, artifacts, experiences, etc.) are sensitive to the context and domain they are created within. Mishra and Koehler [20] term this third construct as 'wholeness' - involving the contextual aspects of creative work, or how well it is fit to that work's specific purpose or context. From both a business and an educational perspective, in these constructs of novelty, effectiveness, and wholeness (NEW), creativity fits well with the goals of effective learning and improvement [21].

The problem of creating learning experiences that are novel (or relatively so, in an instantiation of a course), effective, and whole in business education, is that the variety of business contexts we may be teaching for are subject to variability and change.

Thus, we may not always fully understand what the goals, settings, outcomes, or challenges look like-in order to try to teach students to readily produce creativity in novel, effective, and whole 
products or ways of doing things. It may be more constructive to aim for supporting the development of a creative orientation to the world. In evolving contexts, things change frequently, and we are, often, dealing with uncertainty and unknowns. This is why we suggest that creativity be, instead, defined by a focus on a mindset that corresponds with creative thinking, rather than chasing a moving target of novelty, effectiveness, and wholeness, or seeking perfect creativity. If we start by understanding and aiming for the habits of mind or theoretical components that help support creative development across the lifespan, we are better positioned to produce creative thinkers across the wide range of contexts for business education.

We suggest that there is much of value here around theories of creative self-belief. This is a broad construct describing an individual's beliefs about their own creativity. Theories under this construct help to explain how the essential predictors of whether individuals are able to think, act, and work creatively depends on their own beliefs about themselves as a creative individual [22]. Beghetto and Karwowski [23] suggest that individuals must feel efficacious or see themselves as creative to actually engage creatively. In management literature, there are few studies that focus on how one's beliefs, attitudes, and expectations about creativity might be adjusted to maximize creative performance-so much of the extant literature lies in education or psychology.

Additionally, in grounding ourselves in a creativity worldview, and in defining creativity, we consider certain areas of focus or perspective. In the report All Our Futures by the British National Advisory Committee on Creative and Culture Education [24], Sir Ken Robinson and colleagues introduced three perspectives on creativity. In one, they suggest, "many people associate creativity primarily with the arts ... but creativity is not unique to the arts. It is equally fundamental to advances in the sciences, in mathematics, technology, in politics, business and in all areas of everyday life" [24] (p. 27). Another type of creativity focuses on how people with exceptional creative gifts produce historic theories, inventions, paintings, or compositions-although such creativity is less common. Finally, there is a more democratic definition of creativity that encompasses more people, which is the process of "imaginative activity fashioned so as to produce outcomes that are both original and of value" [24] (p. 30). According to this democratic definition, which most contemporary creativity scholars support [15], all people can be creative in their work and daily life, even if they do not recognize they are being creative. This perspective on creativity is also essential to education, because without it, it is hard to envision building educative experiences that allow people to develop creatively.

In management literature, creativity is not always well defined, but business professor Teresa Amabile's definition is often cited, which suggests that creativity is "the production of novel and appropriate solutions to open-ended problems in any domain of human activity" [25] (p. 18). This definition and most applications in the field of business lean toward a democratic perspective, which suggests that creativity can, and should, be developed by everyone, and acted on as a vital driver for innovation [26].

Thus, we assert that a more democratic perspective on creativity-paired with an aim to support learners in their own beliefs and capacity to act in novel, effective, and whole ways-can be informed by theories of creative self-belief. These theories include creative identity, creative mindset, and creative self-efficacy. In order to better understand the components of creative self-belief, we review several theoretical constructs from educational psychology which we believe may be useful to consider in business education and training. In the following sections, we will delve more deeply into these theories that fall under the heading of creative self-belief.

\section{Guiding Approach to the Literature}

In organizing our approach to this review of the literature, we sought to understand common themes and core ideas about creative self-beliefs. We consider, how are creative self-beliefs defined in the literature? More specifically, we consider this question with an eye toward what elements of creative self-beliefs may relate to, or inform, arts-based creativity training? 
The notion of self-beliefs is a general construct in psychology that describes individuals' beliefs about themselves, in terms of who they are and where their capacities lie. Research on self-beliefs falls under several theory-driven psychological constructs, including: identity theory [27,28], growth mindset theory [29], and self-efficacy theory [30]. These three theories, though all recent in the history of educational psychology, are each significant explanatory concepts on self-beliefs. Because they are meta-theories, they often function as parent concepts, which have smaller unique branches and niche areas of theory offshoots. Of interest to us and our question are three narrower niche areas of research, looking at how identity, mindset, and self-efficacy intersect with creativity.

In order to examine this, we begin each literature section with a brief overview of the 'parent' theory. We sought to summarize the key points of each parent theory based on primary sources. The aim here is to give the reader a brief overview of the landscape of each theory construct, followed by a more detailed look at the creativity-focused branch of that theory. Each parent theory is too broad to be reviewed in a single article. However, more specific areas of intersection with creativity are narrower, as well as more recent and niche, making it possible to examine them in enough depth to understand the basic scope.

We engaged a search of each theoretical branch of creative self-beliefs. Our sources of literature were two given databases, (1) ScienceDirect and (2) Scopus, as these comprise a significant swath of 'mainstream' research papers in English [31].

Tranfield et al. [32] suggest that a methodical search begins with the identification of keywords and search terms, as chosen from the scoping study and the literature, and discussions noted within the review team. The reviewer(s) then choose the search strings that are most appropriate for the study. In this sense, we were able to keep the search relatively straightforward, by using keywords and terms that precisely defined each area, including each of the terms themselves: "creative identity", "creative mindset", and "creative self-efficacy". This yielded articles or studies that specifically referenced the exact theory/terminology within the text. We determined this to be a more appropriate approach for these particular areas than the more expansive Boolean search terms of creativity and identity, creativity and mindset, and creativity and self-efficacy.

We began the initial scoping search with these expanded terms, and found that these produce large volumes of works outside of the scope of each specific theory. For example, the literature search data we display below in Table 1 illustrates the numbers yielded by using the specific theory terms themselves (e.g., "creative mindset"), vs more expanded search (e.g., creativity and mindset).

Table 1. Numbers for specific theory terms.

\begin{tabular}{ccccccc}
\hline & $\begin{array}{c}\text { Creative } \\
\text { Mindset }\end{array}$ & $\begin{array}{c}\text { Creativity } \\
\text { and } \\
\text { Mindset }\end{array}$ & $\begin{array}{c}\text { Creative } \\
\text { Identity }\end{array}$ & $\begin{array}{c}\text { Creativity } \\
\text { and Identity }\end{array}$ & $\begin{array}{c}\text { Creative } \\
\text { Self-Efficacy }\end{array}$ & $\begin{array}{c}\text { Creativity } \\
\text { and } \\
\text { Self-Efficacy }\end{array}$ \\
\hline $\begin{array}{c}\text { Scopus } \\
\text { Science } \\
\text { Direct }\end{array}$ & 33 & 241 & 82 & 1960 & 185 & 384 \\
\hline
\end{tabular}

While the more open Boolean search, which did not specify the theory terminology in "quotes", produced greatly more results in terms of pure numbers, it also produced a vast array of unrelated literature that merely contained those terms in the text. By narrowing down to the proper theory terminology, we were able to identify the relevant works on the topic. Thus, our initial list of potential works was drawn from this. Even within those smaller search scopes of exact theory terminology, there were still significant numbers of articles that were not appropriate for inclusion in our discussion that follows.

Thus, our extended search criteria were narrowed to identify only articles that placed these creative self-belief theories as a focus of study, or a core topic. We aimed to look beyond any articles that simply mentioned the terms within the text, or that dealt with them in peripheral ways that 
offered little in takeaways (e.g., an article that referred to or mentioned "creative identity" would not be included unless it sought to either empirically study the theory, or discuss the concept with some theoretical focus). We were able to narrow our focus to the key articles described in our narrative review, as many articles that popped up in our keyword search simply mentioned these terms in the text, but focused on other topics.

As we examined each initial search to select out articles that put the construct or concept as a central point or area of study, we identified a more selected swath of research in each area. This makes sense, as each of these creative self-belief concepts has emerged primarily within recent decades, and is a small, but promising, area in the larger arena of creativity research. Thus, each made for a small-scope, but interesting, look at issues of creative self-beliefs. These articles are reported below in each section, which is a more of a narrative than purely systematic type of review, which we explain further.

\section{Limitations}

There are some notable limitations in this work. First, we limited our examination to two core databases. Although these are comprehensive sources of academic scholarship in English, and encompass most major and smaller journals that cover creativity research and scholarship, it remains a potential limitation of scope and size.

Further, our own personal biases as educational researchers could have limited us in scoping each of the search terms, as researchers naturally bring in their own preconceptions, assumptions, or interests that may lead to a potential tendency to seek confirming evidence of each theory or area of interest [33].

Most importantly, while we have aimed to systematize and explain our search processes and provide the reader with more clarity on the process and rationale for the review, this review is not a full systematic literature review. We do not aim to present each body of literature as a kind of "data" set for empirical dissection, as the literature on this topic is not necessarily manageable to represent as systematized data, but may be relevantly explored in a traditional narrative review format.

A significant concern with any sort of attempt at systematic review, in this topical context, would be that, in certain areas of creativity research, this type of full systematic method is a methodological impossibility or, at the very least, a fraught challenge. This is due to the nature of the terrains of education and psychology in which creative self-belief literature is often situated. These are areas that are not often built upon the types of clean, positivistic approaches to data and research that are common in medical, business, or scientific fields, in which most systematic reviews originate and, indeed, in which systematic reviews originate as a method. Thus, the literature itself does not always lend itself to conversion into systematic data.

This also presents a limitation within creativity research itself, because although some positivistic and quantifiable studies exist in creativity, they are more often around the psychometrics of creativity or cognitive approaches to creativity. Within the newer and somewhat emergent, exploratory area of creativity and self-beliefs, there are certainly interesting and worthwhile points of scholarship to review and consider, but these are often more inimitable and may be theoretical or qualitatively focused approaches or methods that are less easily empiricized into a full systematic review. As Tranfield et al. [32] note:

Systematic reviews, due to their positivistic origins, sit comfortably with studies that use quantitative methods such as randomized controlled trials, quasi-experimental designs, and cost-benefit and cost-effectiveness studies, therefore, establishing criteria for ascertaining what is "relevant" or "good quality" in qualitative research provides a further challenge [34]. With qualitative studies there is no possibility of testing statistically the significance of the results (p. 216).

Thus, our reporting of each area of literature, as follows, is more narrative than systematically data-driven. Although we do not present a full systematic review method, we have aimed to be methodical about our search process as noted, and clarify the logic of our approach. Through this, we seek to help the reader understand the logical train of approach to each theory, to understand 
significant points of interest that might be culled from each theoretical area, for consideration in creativity and business training.

\section{Examining Theories of Creativity and Self-Belief: Creative Identity, Mindset, and Self-Efficacy}

In promoting creativity in the field of business, it is important to understand factors linked to supporting individuals' creative development from an education perspective. Beghetto and Dilley [22] have noted that one of the most essential drivers of whether individuals are able to think, act, and work creatively, depends on their own self-beliefs about themselves as a creative individual. Without creative self-belief, or a sense of one's potential and ability to be creative, it is difficult to function creatively.

As educational researchers examining creativity in business education and training, we suggest that core theories dealing with self-belief can help us understand what supports creativity. These theoretical foundations involve creative identity, creative mindset, and creative self-efficacy. We review each, then connect this to the value of arts-based interventions and learning in business.

\subsection{Identity Theory}

The primary source originators of identity are Stryker [27] and Burke [28]—and this primary work furthered their later collaborations on the topic. Among primary identity theorists, such as Stryker and Burke [35], the use of the term identity involves components of a view of the self, or the meanings people attach to themselves based on roles they play in contemporary societies. Identity theory points toward either explaining how social structures impact the self [27], or to how the sense of self impacts social behavior [28].

There are two notable points about identity formation. First, an individual has multiple identities that interact with each other based on the systems they operate in. Second, these identities are initially situation-specific but, over time, they are organized into a hierarchy of identities [36]. Their most salient identities are at the top of the hierarchy. Identity salience is defined as the probability that an identity will be invoked across varied situations [35]. Identity theorists have noted how, when an identity has higher salience than other identities, more significant behavioral choices connect to that identity.

\section{Creative Identity}

Creative personal identity (CPI) is defined as "the belief that creativity is an important element in a person's self-definition; and creative role identity is about how important being creative is in each given position" [37] (p. 248).

Studies related to creative personal identity are relatively recent, whereas research measuring "artistic identity" has been studied since the 1970s. Most research on creative identity or related concepts has showed up in the academic domain, focused on K-12 or college students, or in workplace domains focused on company employees. In business journals, effort has been spent toward testing or developing creative thinking skills that correlate with creative behavior, not identity. Importantly, some work on creative identity, thus far, has been linked to the arts.

For instance, in an extension to a study started by Getzels and Csikszenmihali [38], Freeman [39] studied the progress of a graduated group of art students from the mid-1960s to mid-1980s. He concluded that many individuals did not meet their artistic potential because of mythical, unrealistic expectations about being artistic. Debunking such myths and differentiating them from the actual creative process helped artists feel, and be, more creative [40].

Rostan [40] conducted a study exploring children's (ages 8-11) perceptions about being artistic and creative. The children participated in unstructured, open-ended interviews discussing their long-term painting projects and the process of creating art. Albeit a younger population than adults in business, the findings demonstrated salient points of identity production. Rostan's work illustrated how the motivation to work hard at developing a skill, such as creativity, related to an individual's artistic focus and their perception of what it meant to identify as an artist or creative person. Also, 
students perceived their identity as an artist to emerge from the act of producing art, rather than the belief in an innate skill. Toward this point, other studies have also concluded that becoming creative is expressed in terms of incremental learning, rather than as innate properties [41].

In more recent studies targeting adults, Jaussi et al. [37] examined the relationship of creativity at work by exploring creative identity and its relationship with creative self-efficacy and problem-solving. Results suggested that creative identity explained the variance in creativity at work. Also, the positive relationship between creative personal identity and creativity at work was stronger when individuals had opportunities to engage in non-work experiences—such as arts-based activities—and apply these toward solving work-related problems.

There are different ways that some areas of scholarship consider identity with creativity. Some scholars look at the connection more generally, aiming to examine identity states alongside creative production, seeking to study how, or when individuals are prone to being creative, depending on identity issues [42]. Other scholars have sought to look at creative identity as a whole construct, and examine either its precursors [43] or consequences [44]. Others have tried to manipulate social identity in order to discover causal links between identity norms and creativity in certain contexts [45]. Much work on creativity and identity begins with the assumption that creative identity relates to creative performance. The relationship between creativity beliefs about the self and performance is studied under "creative self-efficacy", and we examine this in a later theory section. While both self-efficacy and identity contribute to a more "creative self" factor, identity underpins self-efficacy, and may enhance its effects across contexts [46].

Glăveanu and Tanggaard [47] suggested that creative identities are considered representational projects which emerge in the interaction between self (the creator), multiple others (different audiences), and notions of creativity informed by societal discourses. They note that, in order to properly consider the link between identity and behavior, we must understand more than just how important a given identity (e.g., a creative identity) is for an individual. We need to understand what this identity actually means, for the person.

A relevant concept here, for creative identity, is the idea of a "Voice of Judgment", or, an internal monologue that critically judges our work and actions and affects our willingness to engage creatively. This is predicated on the fact that each human individual has thousands of thoughts on a daily basis; and along with that, comes an internal voice that judges and filters these thoughts. While this idea was not initially coined alongside the term "creative identity", it has since been noted by scholars and practitioners as relevant. In the literature, Ray and Meyers [48] gave a name to this as the Voice of Judgment (or VOJ), which is inextricably tied to our sense of identity. They claim that even a slight decrease in judgment increases an individual's ability to respond more creatively in various situations. This internal voice is the sum of all voices from past experiences in one's life. In order for a creative voice to come though, one must become aware of and address silence, or even destroy their VOJ.

Ray and Meyers [48] suggest that it is possible to silence one's VOJ with concentrated effort. The development of a creative identity at any age is a continuing and dynamic process. In fact, an individual's creativity and personal identity grow and change together, since they develop at critical points in life based on experiences [49]. One method often used in the arts to help people identify and manage their VOJ involves creating a visual representation of the VOJ as a physical entity (through drawing, modelling, or other means). This serves to personify and represent it outside of the individual to help one de-identify with the voice [50] - and this common psychological technique of the VOJ (which is often embodied or worked with in arts-based interventions) has become an intermediary step in beginning to identify and allow creative identity, by acknowledging the views that work against it.

\subsection{Mindset Theory}

The concept of mindset further provides theoretical grounding for creative experiences that enhance self-belief. Mindset describes the effects of the beliefs that people hold about the nature of their intelligence-and with "creative mindset", this is extended to beliefs about their creative abilities. 
"Mindset" is a type of implicit theory-meaning it is a personal construction about a particular phenomenon that resides in the minds of individuals. Sternberg [51] noted that implicit theories must be discovered, rather than invented, because they already exist in people's heads. He investigated beliefs that people held about traits they felt other people ought to have. Dweck, on the other hand, was more interested in beliefs people held about their own abilities [52], and she introduced the term "mindset" as an implicit theory that focused on explaining beliefs about abilities people valued and sought in themselves.

Dweck's original research started in the mid-1970s when she challenged the common belief that intelligent people are born smart. Through empirical studies, she demonstrated that individuals' perceptions about their intellectual abilities could dictate their intellectual achievements. Dweck has provided evidence that people who hold a growth mindset think that intelligence is malleable, intellectual ability is learnable, and talents and abilities can be grown with one's effort and help from others [27]. Mistakes are not viewed as a cause for condemnation but, rather, as information to improve, grow, and develop [53].

On the other hand, people who hold fixed mindsets believe they have a certain amount of intelligence, talent, or ability, with no room to build upon them. Such a belief holds people back from trying new experiences, because fixed mindsets protect an ego identity that does not allow for admitting mistakes [27]. In a fixed mindset, learning, risk-taking, and adaptation drop off, while the need for perfection, or a correct answer, rules [53].

\section{Creative Mindset}

Dweck's mindset research has served as the foundation for researchers to study creative mindsets. Dweck primed the idea that her growth/fixed mindset work is transferable to creativity research by referring to a poll of 143 creativity researchers, noting that perseverance and resilience, produced by the growth mindset, was the top ingredient in creative achievement [27]. Karwowski [54] formally defined "creative mindset" as "beliefs about the [fixed] versus [growth] character and nature of creativity" (p. 62). Karwowski indicates that, like intelligence, people often believe creativity is fixed, and that only a few geniuses are truly creative. Yet, people with growth mindsets believe that creativity is trainable, and can be developed much like other characteristics [55].

The relevance of creative mindsets as separate and unique constructs is often established through three main sources: (1) the examination of belief systems of creativity is necessary, given that intelligence is different than creativity [19]. Thus, people may have different beliefs about the nature of their own creativity than they might about intelligence. (2) Researchers have established that the myth that people are born creative (a fixed creative mindset) is deeply detrimental and harmful to the enhancement of creative performance [14]. (3) There is evidence supporting the construct validity of creative mindsets and their contribution to mindset theory more broadly. One study found that implicit theories of intelligence could not predict creative problem solving, yet a growth creative mindset did positively predict creative problem solving [54].

The more straightforward takeaway is that mindset is important because perceptions of creativity influences an individual's desire to engage in, or disengage from, creative thinking and activities. Prior research has shown people with growth mindsets exert more effort and deal better with failure, as they see it as an opportunity to learn and grow [56]. In fixed mindset, failure is considered a threat, and the risk of failure de-motivates people from engaging in challenging activity [57]. Therefore, creativity researchers expect those who hold growth mindsets to engage in creative tasks, and those with fixed mindsets to avoid tasks that are seen as complex or creative [55].

With respect to identity and mindset, when people do not think that creativity is important in their self-description, they are characterized as having low creative personal identity (CPI) [46]; and they, likely, will not care whether creativity is malleable or fixed [54]. Thus, it is important that people both view creativity as amenable to growth, and that they see it as valuable to their self-description. 
Motivated by previous findings, researchers such as Hass et al. [58] asked if the relationship between mindsets and everyday creative behaviors depended on academic domain. The simple answer was, no-but the strength of the relationships varied across the five domains in this study, which included Arts and Humanities, Business, Education, Life Sciences, and Social and Behavioral Sciences. Specifically, business students a demonstrated negative correlation between fixed mindset and everyday creativity; conversely, they also demonstrated a positive correlation between growth mindset and everyday creativity — even more so than art students—which suggests that promoting growth mindset in business students enhances their everyday creativity, and/or vice-versa.

Puente-Díaz and Cavazos-Arroyo [59] examined the influence of creative mindset on achievement goals, creative self-efficacy, enjoyment, and perceived performance and effort among college business students from Mexico. Their work provides an example of the study of creative mindset on students in a business educational setting. They noted a positive influence of a growth creative mindset on task-approach achievement goals (mastering a given task) and creative self-efficacy (a belief in their creative ability). Interestingly, a fixed creative mindset had a positive influence on other-approach achievement goals (a goal of outperforming others, rather than deep engagement for mastery or creativity within the task). Their work finds that growth creative mindset had a direct, positive influence on creative self-efficacy and the students' perceived performance and effort exerted, as well as an indirect influence on enjoyment. They conclude that holding a growth creative mindset is, thus, related to adaptive motivational and performance creative outcomes in business education settings.

Finally, researchers have viewed mindsets as beliefs related to creativity, but not the same as self-beliefs [55]. Theoretically, mindsets shape self-beliefs and, empirically, have been proven to relate to creative identity and self-efficacy in correlational studies $[54,58,60]$. How people perceive the nature of creativity can shape their self-beliefs, leading them toward either a growth or fixed mindset about learning to operate creatively in tasks. This is critical in training to foster creativity in others. Additionally, prior studies have demonstrated a correlation between creative identity or creative mindset and our third self-belief construct, of creative self-efficacy.

\subsection{Self-Efficacy Theory}

The final theory we deal with, related to creativity and self-belief, is self-efficacy theory. Much like identity and mindset (implicit) theories, self-efficacy theory plays an integral role in determining performance [30,52]. This theory was originally established by Albert Bandura [30], and self-efficacy is defined as "people's beliefs about their capabilities to produce designated levels of performance that exercise influence over events that affect their lives" [61] (p. 1).

The strength of a person's beliefs about their effectiveness in any given task influences their choice of behavior [30]. A person's efficacy expectations or perceived self-efficacy determines how much effort they will exude, and how long they will cope with failure or obstacles. Stronger perceived self-efficacy leads to more effort.

Adding to this correlation, Bandura explains that people fear and avoid threatening situations they know they cannot cope with. However, if they persist against these fears, they will gain corrective experiences and eliminate defensive behavior, while those who do not persist will remain fearful, with self-debilitating expectations.

\section{Creative Self-Efficacy}

In creativity literature, creative self-efficacy is defined as the self-view that one has the ability to produce creative outcomes [62]. When creativity is concerned, some people can perceive creative performance as a threatening and arduous task, especially if they have not built prior mastery in a genre before. As a result, they are less likely to choose activities or settings that push them to be creative.

Other studies have also suggested that higher creative self-efficacy leads to greater creative performance [62]. Empirical work has demonstrated that creative performance is associated with 
creative self-efficacy at the individual level [63], at the team level [64], and within diverse industries, such as education, operations, manufacturing, financial, insurance services, and research and development [37,64-67].

Creative self-efficacy is considered malleable. It can fluctuate with changes in self, task, or social context-related factors [68], and can be influenced by past performance accomplishments, vicarious experiences, verbal encouragement, and emotional states [61]. Even with such fluctuations and influences, empirical studies demonstrate that creative identity has a positive relationship with creative self-efficacy, even though they operate as two distinct psychological constructs [37].

Some scholars have studied creative self-efficacy as one of the antecedents of innovation within business and organizational contexts, and it has been identified as a key driver of employees' innovative behavior. For instance, Hsu et al. [69] found a significant effect of creative self-efficacy on employees' innovative behavior, and Tierney and Farmer [68] reported that creative self-efficacy was a strong predictor of employees' creative performance over time. Newman et al. [70] examined whether entrepreneurial leadership (an approach characterized by the leader influencing and directing team members to recognize and exploit entrepreneurial opportunities) influences the extent to which employees with different levels of creative self-efficacy engage in innovative behaviors. They suggest that the influence of creative self-efficacy on employees' innovative behavior is stronger for employees who work in a team with strong entrepreneurial leadership because entrepreneurial behaviors motivate employees to derive creative ideas and implement them. In short, the contexts and influences in the workplace—such as a leader's approach—demonstrate the capacity of creative self-efficacy to influence business innovation.

Along similar lines, Jaiswal and Dhar [71] investigated the mediating role of innovation climate and moderating role of creative self-efficacy. Their findings demonstrate that employees with high creative self-efficacy resort to creative behavior when they receive a supportive innovation climate. Thus, creative self-efficacy has a key role to play in the innovative capacity of businesses, and it can be maximized through supportive environments that seek to empower creative behaviors.

Other studies within organizations have also found that an employee's creative self-efficacy has a significant effect on the individual's creative behavior or creative outcomes [62,72]. Richter et al. [73] suggest that a strong belief in one's creative-self extensively motivates individuals to seek consultation and guidance in applying creative behavior.

Bandura [30] has emphasized the reciprocal relationship between creative behavior and creative self-efficacy, yet, there are few studies that investigate the interaction effect of creative self-efficacy in predicting employee creative behavior. Richter et al. [73] also recommended study the interaction effect of creative self-efficacy. They assert that a strong belief in creative self extensively motivates individuals to seek consultation and guidance in applying creative behavior.

Interestingly, the interaction effect between creative self-efficacy and creative behavior suggests that the effect goes both ways, and that engaging in creative behaviors may lead to enhancement of creative self-efficacy, as well. Bandura's self-efficacy theory provides an understanding that cognition associated with creativity plays an important role in the acquisition and retention of behaviors. Thereby, it becomes incumbent on business education to provide opportunities to support creative self-efficacy, if creative behaviors are desired in the workplace.

\section{Findings: Bringing Together Creative Self-Belief Theories and Arts-Based Methods}

We have considered several key theories from educational psychology, to better understand the importance of developing creative self-belief in business settings. Theories that deal with creative self-belief-such as identity, mindset, and self-efficacy-emphasize the importance of promoting a sense of the self as a creative person with creative capacity.

Our guiding questions for this literature sought to explore these areas of creative self-belief, with an eye toward how creative self-beliefs may relate to, or inform, arts-based creativity training. 
A common finding or narrative of the literature, that ties together each of these reviews of theory, suggests that, for someone to transform their creative potential into creative action, they must have confidence in their ability to act creatively and believe that there is value in doing so. Without this, there is little chance that they will be able to reach their creative potential, or even that they will seek to engage in creative behaviors or creative thinking [22]. Creative self-efficacy was shown to be a driver of innovation in organizational contexts [69-71], but it also deeply connects to creative identity and mindset. This is an important takeaway in reviewing the literature-in noting that these theories often work in reciprocal ways, and work to affect each other within an individual's construction of their own self-beliefs. Any of these areas can be influenced in an individual's psychology by mediating experiences, and a change in one can effect changes in other areas. For instance, bolstering one area, such as creative identity, tends to have an enhancement effect on creative self-efficacy; or, a shift in creative mindset (in terms of one's beliefs about the nature of creativity) can relate to a shift in where creativity falls in one's own identity. Thus, these theories have a synthesizing effect within individuals' creative self-beliefs. This demonstrates the ways that working on developing one area can have relational effects on others. But, more importantly, to truly form a stronger vision of creativity within people's self-beliefs, we must promote or provide educative experiences that seek to enhance or expand each of these theoretical spaces within human psychology.

Thus, creative self-belief theories align to suggest that, if the field of business seeks to promote more creativity from within, there is a need to engage people in educational activities that support creative self-beliefs. While there are many ways to do this, one key approach we suggest and explore further, as follows, is through the integration of arts-based methods.

Arts-based methods, or the incorporation of techniques and processes derived from the arts, have grown in interest in business education and training settings in recent decades [74]. Despite a common misperception that business and the arts have little to do with each other, business can learn from the arts, and successful artists and managers or leaders often share common characteristics-thus, business fields can develop and grow their creative and inventive capacity through connecting to the arts.

This, in some ways, represents a broader aim to cross-fertilize ideas between business and the arts [75]. Along these lines, Formica [76] notes that the most essential and challenging problems in management are not technical, but human-centered, in nature. In this, they may be supported by engagement with creative endeavor and different types of entrepreneurial identity [77]. Taylor and Ladkin [78] describe four different processes or goals in using arts-based methods in business settings. These include skills transfer (the development of skills from the arts to improve performance in business settings), projective technique (using the arts to reveal inner thoughts and perceptions that may not be otherwise accessible), illustration of essence (using the arts to understand the "essence" of an idea), and making (using the arts to foster a deeper experience of personal presence and connection to help managers and leaders experience themselves and their world in a more cohesive way).

While all of these four processes, identified by Taylor and Ladkin, could become critical functions of the arts in business, one that may be interesting to consider, when we aim to strengthen elements of creative self-belief, is the projective technique process. In this, the act of using art becomes a way to "foster reflection through projection" [78] (p. 58).

There is a relevant connection here to constructions of mindset-albeit not from an educational psychology standpoint, and not in the same sense as "creative mindset" in terms of psychological self-belief theories-when they note wherein, Taylor and Ladkin [78] note Langer's contention that "the primary function of art is to objectify experience so that we can contemplate and understand it" [78] (p. 58). In other words, in their conception, making or using art becomes a way to reflect about our own experience, allowing the individual to objectify their world sans limitation or logic already set up by their life. One can view, or make, an object for what it is (fixed mindset) or one can view additional uses and potential that goes beyond the obvious (growth mindset). 
This viewpoint is inspired by the work of Paul Crowther [79], who suggests that the aforementioned process is possible because "the creation of artifacts, or engagement with such artifacts ... enables us to articulate the structures of attention, apprehension, and projection in a way that draws on our cognitive and perceptual capacities operating as a unified field-rather than our intellectual capacities alone" [78] (p. 58).

This idea can also be a way to strengthen creative identity as art objects that people create or engage with can open up a window to the unconscious [80] and, depending on cognitive and perceptional capacities, one can project varied viewpoints, as capacities vary and are colored by past experiences and environmental factors.

When it comes to self-efficacy, however, people's creativity is most often inhibited by fear, negative personal judgement, and chattering of the mind [48]. The key to personal creativity is to eliminate, or at least minimize, these limitations, to allow one's creative essence rather than the ego, false personality, or external self, to project tacit knowledge. This technique indirectly uncovers falsehoods or fixed mindsets, through its creative awakening process. Springborg [81] explored arts-based methods using theories grounded in an embodied view of cognition, and determined that focusing on sensory experience enabled participants to remove judgments about the self and about others. This ability to suspend judgment may have relevance to the concept of the "Voice of Judgment" noted earlier, which must be suspended or silenced, in order for creative identity to flourish.

With respect to management literature, the projection technique, as an arts-based method, has been used in various organizational settings, such as to make invisible concepts like "culture" visible [82], or leveraging the tool called Visual Explorer, where individuals choose an image that best depicts a problem, and discuss the issue together to uncover various viewpoints [83], or use LEGOs to build an organizational strategy [84].

In essence, the projective technique relies more on one's "gut feeling" rather than rational thought [78]. By reflecting on and working with the object, the "knowing in the gut" may be intellectualized into "knowing in the head", Arguably, through time this may be a way to build a belief system within an individual that strengthens their own creative capacities.

This illustrates a potential relationship to creative self-belief-and, thereby, to cognitive processes such as creative identity, mindset, and self-efficacy. It directly references how engagement in the arts is not a one-directional act but, rather, is a bi-directional and symbiotic action of self meaning-making. The act of reflecting might also be extended beyond the original intent, into an act of identity formation, in which a person (an employee, leader, or manager) can begin to see themselves as having a creative identity through the action of engaging in the arts. In this, they may expand their own creative potential and ability, as suggested by Beghetto and Karwowski [23]. Springborg [85] also explores the idea of leadership as art as a phenomenon characterized by leaders working from their senses, rather than drawing on prior modes of sense-making, and by sense-making as a tactile and sensory process, rather than a solely analytical or cognitive one.

Creative identity and self-efficacy are positively correlated, and tend to increase or decrease together, suggesting that, if people engage in activities that enhance their identity in an area, they will also experience an increase in self-efficacy in that area [37]. As we have noted, Karwowski's work [54] suggests that creative mindset is influenced by these elements, also-it is important that people both view creativity as amenable to growth, learning, and change, and to see it as part of a self-description.

All of these elements of self-belief, taken together, are thus amenable to influence by engaging in the arts. While scholars point out the varied ways that the arts can be valuable in business education, training, and development [78], we emphasize their influence on creative self-beliefs. This aligns with the instrumental goals of business education, toward developing a more creative 21st century workforce. But, it also allows for a more human-centered approach to business, in which employees and students can engage in work that is innately human, productive, and creatively fulfilling, toward becoming more self-actualized and creative people [86]. 
Despite the growing interest in arts-based methodologies, and work that suggests their value toward developing creativity, several scholars have pointed out that there remains a lack of empirically grounded work in this area [87], and that more attention is needed toward arts-based methodologies in business, to better understand the experiences of participants.

While the practice of arts-based learning in business is growing, there is a need to better understand how this, and other, methodologies might be used to enhance areas of creative self-belief (i.e., identity, self-efficacy, and mindset). To this end, in the next section, we describe the design of an in-progress intervention with arts-based methods, for developing creative self-belief among business students at the Thunderbird School of Global Management at ASU.

\section{Current and Future Directions: Enhancing Business Students' Creativity}

The authors are engaged in the execution of an action research intervention focused on student creativity training for students in the Thunderbird School of Global Management at Arizona State University. Given that we have discussed creative self-belief theories and proposed their relevance for creativity training in business, we now describe an example of an intervention model we are currently working with. This work will explore the influence of creativity workshops (which include a mix of arts-based and other methods) on business students' perceptions of creative identity, creative mindset, and creative self-efficacy. The project is in progress at the time of writing, so this paper does not focus on data outcomes, but simply concludes by sharing it as an example of an intervention design that explores these creative self-belief constructs in the context of business education and arts-based methods.

This first author of this article is the designer and leader of this project and inquiry, in her role with global recruiting. As a Thunderbird School of Global Management recruiter with eleven years of industry experience, she observed many organizations' lack of understanding of, and appreciation for, fostering creativity via an inside-out approach. Therefore, this project seeks to address this by developing a training program that might address the gap.

The incoming freshman class that are participating in this intervention will graduate into and enter a workforce comprised of over $50 \%$ knowledge-work jobs, which will require them to be social, emotional, creative, and relational. This creativity-focused workshop series was designed to empower students to understand the preconditions of being creative, to utilize their talents, education, and life experiences, and to be the change agents they set out to be.

The Thunderbird School of Global Management at Arizona State University has been historically recognized for its graduate program, currently ranked 7th in the United States for international business specialty [88]. The prestige of the school's reputation has crossed over to its bachelor's degree programs, as many faculties teach both at the bachelor and master's level. In addition, ASU has ranked number one in the United States for the most innovative university from 2016 to 2018. Freshman students are required to take a 1-credit first-year seminar course at the beginning of their program, and this creativity training/intervention will be part of the seminar.

Currently, Thunderbird's freshman seminar curriculum does not include any explicit course objective to teach about creativity or consider students' creativity as a skillset. Therefore, this project seeks to offer creativity training (incorporating arts-based and other methods), and to also evaluate business students' perceptions about their personal everyday creativity, based on associated variables, i.e., creative identity, creative self-efficacy, and creative mindset theories. The goal is to set the tone and serve as initial steps toward developing students' creative competency throughout the entire program, as students move toward becoming global business leaders; ideally, the training may later be scaled up or infused throughout Thunderbird programs.

\subsection{The C3 Innovation Project}

For simplicity, this creativity intervention is called "C3 innovation", based on the three creative self-belief constructs. Within this partially arts-based intervention, we will also seek to collect and 
evaluate data for the action research purposes of understanding the effects of such training on these self-beliefs (e.g., as part of the project, we will employ a concurrent mixed method research design with qualitative and quantitative data).

The C3 project is designed to (a) evaluate students' perceptions about their personal everyday creativity and (b) empower them with strategies to enhance their understanding of the importance of being creative. The project was inspired by a study from Hass et al. [58], in which they measured fixed and growth creative mindsets, and the relationship to creative self-efficacy and creative identity, to create a model of a more complete picture of people's self-perceived creative competencies. The researchers concluded that these constructs are separate but interrelated constructs, and students with high creative self-efficacy tended to endorse creative growth mindsets.

This project will include three phases: educate (training), survey, and interview. We focus on describing the face-to-face training, as an example of intervention work in this area of arts-based training in business but, also, share a few details of how we will collect data, to reflect the evaluative nature of such work.

\subsubsection{Educate Phase}

During the educate phase, there are three facilitated workshops every week, focusing first on creative mindset, then creative identity and, finally, creative self-efficacy. Participants will be tasked to learn concepts and participate in methods and tools in each workshop-engaging in some arts-based, as well as self-reflective/reflexive and other creativity training techniques-and working on related homework and supplemental learnings to aid their comprehension. Also, at the end of each workshop, participants will provide feedback.

In the creative mindset workshop, students will be tasked to enhance their neuroplasticity by utilizing arts-based methods. As an example, in one exercise, the students will draw a personal vision statement for the next five years. Another mindfulness exercise will allow them to meditate via repetition of mantras such as "I will live a creative life, I will ..." . Another exercise will allow students to create a personal artistic-digital gratitude journal via Instagram, where they can select any digital images they wish to create into a montage or collage of image-based perceptions of creativity with respect to their own lives, and to share why they are grateful.

In the creative identity workshop, the students will learn how their identity informs ideation. In one exercise, students will list all possible identities connected to them, e.g., brother, student, etc., then they will select a random object provided by the facilitator and come up with as many ideas as possible and discuss. The point is to exchange ideas and see that they are coming up with different ideas because of the identities they assume. Another exercise involves constructing a visual representation to represent a personification of their Voice of Judgment. By creating and objectifying the voice that limits their creativity, students will engage in discussion about how to separate that critical voice from their own self-perception-to manage or control the voice, so it does not deter them from engaging in the creative process. The final exercise is to develop a list of people who motivate them to be successful in every facet of their lives. In other words, this is to develop a counter to the VOJ, as a Voice of Persistence (VOP), i.e., people who they can keep close to persist in developing a creative sense of self.

In the creative self-efficacy workshop, the students will engage in a theatre-based improv game called "yes, and", where they will complete sentences in pairs by adding "yes, and" in the first round. Next, they will say "yes, but" where they will see how such a simple phrase kills ideas during conversations, and how they should be aware of it. Along this same line of theatre technique, they will also engage in another improv game where pairs will share their passion and interests in $30 \mathrm{~s}$, and then sketch out a startup idea in three minutes. The aim of this game is show how easy it can be to ideate and visualize ideas. The final exercise is called the 1,2, 3 game, where students will number off 1, 2, 3 until somebody makes a mistake. The game will incrementally become harder in further rounds. The point is that posture affects how we feel about making mistakes. In the game, the 
students are encouraged to take a celebratory at the end of their routine to celebrate their mistakes and, most importantly, to then reflect on what can be learned in mistake-making to iterate toward their next moves.

\subsubsection{Survey Phase}

During the survey phase, the participants will respond to three online surveys. The first survey is a post-workshop feedback survey after each of the three workshops, to assess its effectiveness and capture how, or to what extent, these workshops helped students understand creativity and its preconditions related to their creative potential and self-belief. The second survey, offered immediately after the third workshop, will assess their self-perceived everyday creative competencies, measuring the three constructs of creative identity, creative mindset, and creative self-efficacy. The third survey, a retrospective pre-intervention version, administered a week later, will evaluate the same three constructs assessed on the post-intervention survey. The retrospective survey lets students to respond to the same survey items, but they are asked to think back to the beginning of the semester, before the intervention. They rate the items using the same criteria they had learned through participating in the creativity workshops, to avoid a response shift bias.

\subsubsection{Interview Phase}

During the interview phase, we purposively sample eight to ten students one week after the workshop and surveys are completed. The interviews aim to help us better understand the results of employing such an intervention, through understanding (a) perceived vs real limitations and/or inhibitors/motivators of everyday creativity, and (b) examples of each students' personal everyday creativity before or during college, to inform future iterations of professional development creativity workshops, and (c) to evaluate the intervention and what aspects of the creativity training may be useful to include or adapt in the future.

We share the design of this creativity intervention as an example of ongoing work that seeks to connect constructs related to creative self-beliefs and consider where creativity training, including arts-based methods, may be instantiated in business education, training, and research.

\section{Conclusions}

We have drawn a connection between calls for a more creative workforce and the potential of arts-based methods in business education, focusing on the importance of theories of creative self-belief, including creative identity, creative mindset, and creative self-efficacy. The popularity of business as a major has steadily risen in recent decades; and there has also been a realization, in popular and scholarly discourse, about the need to develop skills, aptitudes, and inclination toward creativity among employees, leaders, and managers in business. It is incumbent upon business education, professional development, and training, to incorporate methodologies that enhance creative capacity. But, this is easier said than done, and it is important to consider methods and approaches-particularly in the arts-toward building creative capacity in business students and employees.

We have asserted that it may be beneficial to consider theories from psychology and education that explain conditions and elements related to thinking, working, and acting creatively. Specifically, in this literature review, we focused on three theoretical constructs related to creative self-belief (or the beliefs that individuals have about their own creativity). By reviewing these theories, we examine constructs that comprise what it means to identify as a creative person, and to value and believe in one's own creative capacity. Literature in these areas points to creative self-belief as a key to unlocking an individual's creative potential, and to the deep interconnections between creative identity, mindset, and self-efficacy, which can be explored and used to enhance individuals' capacity with business education settings. Notably, the findings around these theories imply that they often relate to and affect each other within individual human psychology. Thus, working to expand or bring forward any facet of creative self-beliefs may enhance others. A more cohesive and strong effect may be possible 
through interventions that seek to work upon all three theoretical aspects of creativity and self-beliefs (e.g., one example is found in the $\mathrm{C} 3$ instance we have shared here).

While there are varied pathways to expanding creative self-belief, one common theme that recurs is in arts-based methods. Richards [89] and others point to the ways that engaging in the arts is valuable toward constructing a creative sense of self and giving people new ways of viewing the world and working, thinking, and acting creatively within it.

Arts-based methods are a vital area of growth in business scholarship and practice, and while much work has already pointed to their potential, many have also pointed to the need to expand theoretical and empirical work in this area. We have shared one example of an intervention project in progress aimed at investigating this area of arts-based and other methods toward creative self-belief. As more work grows in this area, it will be important to consider multiple ways of knowing and understanding the world as a creative person, and this is an area in which business and education can inform each other, living and thriving at the crossroads of creativity.

Author Contributions: S.H. contributed as author in conceptualization, methodology, writing-original draft preparation, writing-review and editing, and project administration. D.H. contributed as author in conceptualization, writing—original draft preparation, writing-review and editing, and supervision of writing.

Funding: This research received no external funding.

Acknowledgments: We acknowledge with appreciation the support of Thunderbird School of Global Management at Arizona State University, which provided the context and opportunity to actualize this work, and the intervention described in this paper. In addition, Ray Buss of Arizona State University deserves thanks for supporting this ongoing work as Dissertation Chair and advisor. Finally, we offer a special thanks to the guest editors of this special issue, Beibei Song, Claus Springborg, and Piero Formica, for all of their efforts to bring forward more work around arts-based learning in business. We also thank the reviewers, including Claus Springborg, who provided thoughtful comments toward the revision and strengthening of this article.

Conflicts of Interest: The authors declare no conflict of interest.

\section{References}

1. Barroso-Tanoira, F.G. Motivation for increasing creativity, innovation and entrepreneurship. An experience from the classroom to business firms. J. Innov. Manag. 2017, 5, 55-74.

2. Florida, R. The Rise of the Creative Class—Revisited: Revised and Expanded; Basic Books (AZ): New York, NY, USA, 2014.

3. Schlee, R.P.; Harich, K.R. Teaching creativity to business students: How well are we doing? J. Educ. Bus. 2014, 89, 133-141. [CrossRef]

4. Zhao, Y. World Class Learners: Educating Creative and Entrepreneurial Students; Corwin Press: Thousand Oaks, CA, USA, 2012.

5. Pink, D.H. A Whole New Mind: Why Right-Brainers Will Rule the Future; Penguin: London, UK, 2006.

6. Boulocher-Passet, V.; Daly, P.; Sequeira, I. Fostering creativity understanding: Case study of an exercise designed for a large undergraduate business cohort at EDHEC Business School. J. Manag. Dev. 2016, 35, 574-591. [CrossRef]

7. The Association to Advance Collegiate Schools of Business (AACSB). A Collective Vision for Business Education. Available online: http://www.aacsb.edu/-/media/managementeducation/docs/collectivevision-for-business-education.ashx?la=en (accessed on 20 July 2018).

8. Davenport, T.H. Thinking for A Living: How to Get Better Performance and Results from Knowledge Workers; Harvard Business School Press: Boston, MA, USA, 2005.

9. Hogan, A.; Roberts, B. Occupational Employment Projections to 2024; Monthly Labor Revie, U.S. Bureau of Labor Statistics: Washington, DC, USA, 2015. Available online: https:/ /www.bls.gov/opub/mlr/2015/ article/occupational-employment-projections-to-2024.htm (accessed on 14 April 2018).

10. Slayton, S.C.; D'Archer, J.; Kaplan, F. Outcome studies on the efficacy of art therapy: A review of findings. Art Ther. 2010, 27, 108-118. [CrossRef]

11. Stuckey, H.L.; Nobel, J. The Connection Between Art, Healing, and Public Health: A Review of Current Literature. Am. J. Public Health 2010, 100, 254-263. [CrossRef] [PubMed] 
12. Kelley, T.; Kelley, D. Creative Confidence: Unleashing the Creative Potential Within US All; Crown Business: New York, NY, USA, 2013.

13. Paulus, P.B.; Yang, H.C. Idea generation in groups: A basis for creativity in organizations. Organ. Behav. Hum. Decis. Process. 2000, 82, 76-87. [CrossRef]

14. Plucker, J.A.; Beghetto, R.A.; Dow, G.T. Why isn't creativity more important to educational psychologists? Potentials, pitfalls, and future directions in creativity research. Educ. Psychol. 2004, 39, 83-96. [CrossRef]

15. Runco, M.A. Creativity: Theories and Themes: Research, Development, and Practice; Elsevier: Amsterdam, The Netherlands, 2014.

16. Cropley, A.J. Creativity in Education E Learning; Routledge Falmer: Bodmin, UK, 2003.

17. Amabile, T.M. How to Kill Creativity; Harvard Business School Publishing: Boston, MA, USA, 1998; Volume 87, pp. 81-84.

18. Zhou, J.; George, J.M. When job dissatisfaction leads to creativity: Encouraging the expression of voice. Acad. Manag. J. 2001, 44, 682-696.

19. Sternberg, R.J.; O'Hara, L.A. 13 Creativity and Intelligence. In Handbook of Creativity; Cambridge University Press: Cambridge, UK, 1999; p. 251.

20. Mishra, P.; Koehler, M.J. Introducing technological pedagogical content knowledge. In Proceedings of the Annual Meeting of the American Educational Research Association, New York, NY, USA, 24-28 March 2008; pp. 1-16.

21. Henriksen, D.; Mishra, P.; Mehta, R. Novel, effective, whole: Toward a NEW framework for evaluations of creative products. J. Technol. Teach. Educ. 2015, 23, 455-478.

22. Beghetto, R.A.; Dilley, A.E. Creative aspirations or pipe dreams? Toward understanding creative mortification in children and adolescents. New Dir. Child Adolesc. Dev. 2016, 2016, 85-95. [CrossRef] [PubMed]

23. Beghetto, R.A.; Karwowski, M. Toward untangling creative self-beliefs. In The Creative Self; Academic Press: Cambridge, MA, USA, 2017; pp. 3-22.

24. NACCCE. All our Futures: Creativity, Culture and Education. 1999. Available online: http:/ / sirkenrobinson. com/pdf/allourfutures.pdf (accessed on 19 September 2018).

25. Amabile, T. Entrepreneurial Creativity Through Motivational Synergy. J. Creative Behav. 1997, 31, 18-26. [CrossRef]

26. Cropley, A.J.; Cropley, D. Fostering Creativity: A Diagnostic Approach for Higher Education and Organizations; Hampton Press: Cresskill, NJ, USA, 2009.

27. Stryker, S. Identity Theory: A Social Structural Version; The Blackburn Press: Caldwell, NJ, USA, 1980.

28. Burke, P.J. Identity processes and social stress. Am. Sociol. Rev. 1991, 56, 836-849. [CrossRef]

29. Dweck, C.S. Mindset: The New Psychology of Success; Random House Digital, Inc.: New York, NY, USA, 2008.

30. Bandura, A. Self-efficacy: Toward a unifying theory of behavioral change. Psychol. Rev. 1977, 84, 191. [CrossRef] [PubMed]

31. Naumann, C. Entrepreneurial Mindset: A Synthetic Literature Review. Entrep. Bus. Econ. Rev. 2017, 5, 149-172. [CrossRef]

32. Tranfield, D.; Denyer, D.; Smart, P. Towards a methodology for developing evidence-informed management knowledge by means of systematic review. Br. J. Manag. 2003, 14, 207-222. [CrossRef]

33. Chenail, R.J. Interviewing the investigator: Strategies for addressing instrumentation and researcher bias concerns in qualitative research. Qual. Rep. 2011, 16, 255-262.

34. Engel, J.D.; Kuzel, A.J. On the idea of what constitutes good qualitative inquiry. Qual. Health Res. 1992, 2, 504-510. [CrossRef]

35. Stryker, S.; Burke, P.J. The past, present, and future of an identity theory. Soc. Psychol. Q. 2000, 63, $284-297$. [CrossRef]

36. Burke, P.J.; Tully, J.C. The measurement of role identity. Soc. Forces 1977, 55, 881-897. [CrossRef]

37. Jaussi, K.S.; Randel, A.E.; Dionne, S.D. I am, I think I can, and I do: The role of personal identity, self-efficacy, and cross-application of experiences in creativity at work. Creativity Res. J. 2007, 19, 247-258. [CrossRef]

38. Getzels, J.W.; Csikszentmihalyi, M. The Creative Vision; John Wiley \& Sons: Hoboken, NJ, USA, 1976.

39. Freeman, M. Finding the Muse: A Sociopsychological Inquiry into the Conditions of Artistic Creativity; Cambridge University Press: Cambridge, UK, 1993.

40. Rostan, S.M. A study of the development of young artists: The emergence of on artistic and creative identity. J. Creat. Behav. 1998, 32, 278-301. [CrossRef] 
41. Dweck, C.S.; Leggett, E.L. A social-cognitive approach to motivation and personality. Psychol. Rev. 1988, 95, 256. Available online: http:/ /login.ezproxy1.lib.asu.edu/login?url=https:/ / search-proquest-com.ezproxy1. lib.asu.edu/docview/1290957036?accountid=4485 (accessed on 15 September 2018). [CrossRef]

42. Barbot, B. Identity structures and creative expression in adolescence. Orientat. Sc. Prof. 2008, 37, $483-507$.

43. Farmer, S.M.; Tierney, P.; Kung-Mcintyre, K. Employee creativity in Taiwan: An application of role identity theory. Acad. Manag. J. 2003, 46, 618-630.

44. Hirst, G.; Van Dick, R.; Van Knippenberg, D. A social identity perspective on leadership and employee creativity. J. Organ. Behav. Int. J. Ind. Occup. Organ. Psychol. Behav. 2009, 30, 963-982. [CrossRef]

45. Adarves-Yorno, I.; Postmes, T.; Haslam, S.A. Creative innovation or crazy irrelevance? The contribution of group norms and social identity to creative behavior. J. Exp. Soc. Psychol. 2007, 43, 410-416. [CrossRef]

46. Karwowski, M. Did curiosity kill the cat? Relationship between trait curiosity, creative self-efficacy and creative personal identity. Eur. J. Psychol. 2012, 8, 547-558. [CrossRef]

47. Glăveanu, V.P.; Tanggaard, L. Creativity, identity, and representation: Towards a socio-cultural theory of creative identity. New Ideas Psychol. 2014, 34, 12-21. [CrossRef]

48. Ray, M.L.; Myers, R. Creativity in Business; Main Street Books: Minot, ND, USA, 1986.

49. Albert, R.S. Identity, experiences, and career choice among the exceptionally gifted and eminent. In Theories of Creativity; Runco, M.A., Albert, R.S., Eds.; Sage Publications: Thousand Oaks, CA, USA, 1990; Volume 115, pp. 13-34.

50. Dobson, C. Wandering and Direction in Creative Production. In The Oxford Handbook of Spontaneous Thought: Mind-Wandering, Creativity, and Dreaming; Fox, K., Christoff, K., Eds.; Oxford University Press: Oxford, UK, 2018.

51. Sternberg, R.J. Implicit theories of intelligence, creativity, and wisdom. J. Pers. Soc. Psychol. 1985, $49,607$. [CrossRef]

52. Dweck, C.S.; Chiu, C.Y.; Hong, Y.Y. Implicit theories and their role in judgments and reactions: A word from two perspectives. Psychol. Inq. 1995, 6, 267-285. [CrossRef]

53. Hunter, J.; Scherer, J.S. Knowledge worker productivity and the practice of self-management. In The Drucker Difference: What the World's Greatest Management Thinker Means to Today's Business Leaders; McGraw-Hill Education: New York, NY, USA, 2009; pp. 175-194.

54. Karwowski, M. Creative mindsets: Measurement, correlates, consequences. Psychol. Aesthet. Creat. Arts 2014, 8, 62-70. [CrossRef]

55. Karwowski, M.; Brzeski, A. Creative mindsets: Prospects and challenges. In The Creative Self; Karwowski, M., Kaufmann, J.C., Eds.; Academic Press: San Diego, CA, USA, 2017; pp. 367-383.

56. Burnette, J.L.; O’Boyle, E.H.; VanEpps, E.M.; Pollack, J.M.; Finkel, E.J. Mind-sets matter: A meta-analytic review of implicit theories and self-regulation. Psychol. Bull. 2013, 139, 655-701. [CrossRef] [PubMed]

57. Haimovitz, K.; Wormington, S.V.; Corpus, J.H. Dangerous mindsets: How beliefs about intelligence predict motivational change. Learn. Individ. Differ. 2011, 21,747-752. [CrossRef]

58. Hass, R.W.; Katz-Buonincontro, J.; Reiter-Palmon, R. Disentangling creative mindsets from creative self-efficacy and creative identity: Do people hold fixed and growth theories of creativity? Psychol. Aesthet. Creat. Arts 2016, 10, 436. [CrossRef]

59. Puente-Díaz, R.; Cavazos-Arroyo, J. The influence of creative mindsets on achievement goals, enjoyment, creative self-efficacy and performance among business students. Think. Ski. Creat. 2017, 24, 1-11. [CrossRef]

60. Pretz, J.E.; Nelson, D.N. Creativity is influenced by domain, creative self-efficacy, self-efficacy, and self-esteem. In The Creative Self; Karwowski, M., Kaufmann, J.C., Eds.; Academic Press: San Diego, CA, USA, 2017; pp. 156-169.

61. Bandura, A. Self-efficacy. In Encyclopedia of Human Behavior; Ramachaudran, V.S., Ed.; Academic Press: New York, NY, USA, 1994; Volume 4, pp. 71-81.

62. Tierney, P.; Farmer, S.M. Creative self-efficacy: Its potential antecedents and relationship to creative performance. Acad. Manag. J. 2002, 45, 1137-1148.

63. Tierney, P.; Farmer, S.M. The Pygmalion process and employee creativity. J. Manag. 2004, 30, 413-432. [CrossRef]

64. Shin, S.J.; Zhou, J. When is educational specialization heterogeneity related to creativity in research and development teams? Transformational leadership as a moderator. J. Appl. Psychol. 2007, 92, 1709. [CrossRef] [PubMed] 
65. Beghetto, R.A. Creative self-efficacy: Correlates in middle and secondary students. Creat. Res. J. 2006, 18, 447-457. [CrossRef]

66. Carmeli, A.; Schaubroeck, J. The influence of leaders' and other referents' normative expectations on individual involvement in creative work. Leadersh. Q. 2007, 18, 35-48. [CrossRef]

67. Choi, J.N. Individual and contextual predictors of creative performance: The mediating role of psychological processes. Creat. Res. J. 2004, 16, 187-199. [CrossRef]

68. Tierney, P.; Farmer, S.M. Creative self-efficacy development and creative performance over time. J. Appl. Psychol. 2011, 96, 277. [CrossRef] [PubMed]

69. Hsu, M.; Hou, S.; Fan, H. Creative self-efficacy and innovative behavior in a service setting: Optimism as a moderator. J. Creat. Behav. 2011, 45, 258-272.

70. Newman, A.; Herman, H.M.; Schwarz, G.; Nielsen, I. The effects of employees' creative self-efficacy on innovative behavior: The role of entrepreneurial leadership. J. Bus. Res. 2018, 89, 1-9. [CrossRef]

71. Jaiswal, N.K.; Dhar, R.L. Transformational leadership, innovation climate, creative self-efficacy and employee creativity: A multilevel study. Int. J. Hosp. Manag. 2015, 51, 30-41. [CrossRef]

72. Gong, Y.; Huang, J.C.; Farh, J.L. Employee learning orientation, transformational leadership, and employee creativity: The mediating role of employee creative self-efficacy. Acad. Manag. J. 2009, 52, 765-778. [CrossRef]

73. Richter, A.W.; Hirst, G.; Van Knippenberg, D.; Baer, M. Creative self-efficacy and individual creativity in team contexts: Cross-level interactions with team informational resources. J. Appl. Psychol. 2012, 97, 1282. [CrossRef] [PubMed]

74. Nissley, N. Arts-based learning at work: Economic downturns, innovation upturns, and the eminent practicality of arts in business. J. Bus. Strategy 2010, 31, 8-20. [CrossRef]

75. Adler, N.J. The arts \& leadership: Now that we can do anything, what will we do? Acad. Manag. Learn. Educ. 2006, 5, 486-499.

76. Formica, P. Entrepreneurial Renaissance; Springer: Dordrecht, The Netherlands, 2017.

77. Formica, P. The Role of Creative Ignorance: Portraits of Path Finders and Path Creators; Springer: Dordrecht, The Netherlands, 2014.

78. Taylor, S.S.; Ladkin, D. Understanding arts-based methods in managerial development. Acad. Manag. Learn. Educ. 2009, 8, 55-69. [CrossRef]

79. Crowther, P. Art and Embodiment: From Aesthetics to Self-Consciousness; Clanendon Press: Oxford, UK, 1993.

80. Malchiodi, C.A. Understanding Children's Drawings; Guilford Press: New York, NY, USA, 1998.

81. Springborg, C. Art-Based Methods in Management Education. Ph.D. Thesis, Cranfield University, Bedford, UK, 2014.

82. Linstead, S. Exploring culture with The Radio Ballads: Using asethetics to facilitate change. Manag. Decis. 2006, 44, 474-485. [CrossRef]

83. Palus, C.J.; Horth, D.M. Visual Explorer: Picturing Approaches to Complex Challenges; CCL Press: Greensboro, NC, USA, 2001.

84. Burgi, P.; Roos, J. Images of strategy. Eur. Manag. J. 2003, 21, 69-78. [CrossRef]

85. Springborg, C. Leadership as art-leaders coming to their senses. Leadership 2010, 6, 243-258. [CrossRef]

86. Dissanayake, E. Art and Intimacy: How the Arts Began; University of Washington Press: Seattle, WA, USA, 2000.

87. Sutherland, I.; Purg, D. Arts-based leadership development at the IEDC-Bled School of Management. Bus. Leadersh. Rev. 2010, 7, 34-40.

88. U.S. News and World Report. Best International MBA Programs. 2018. Available online: https://www. usnews.com/best-graduate-schools/top-business-schools/international-business-rankings (accessed on 19 September 2018).

89. Richards, D. Artful Work: Awakening Joy, Meaning and Commitment in the Workplace; Berrett-Koehler: San Francisco, CA, USA, 1995.

(C) 2018 by the authors. Licensee MDPI, Basel, Switzerland. This article is an open access article distributed under the terms and conditions of the Creative Commons Attribution (CC BY) license (http:/ / creativecommons.org/licenses/by/4.0/). 